\title{
Scaling the User Base of Digital Ventures Through Generative Pattern Replication: The Case of Ridesharing
}

\author{
Bozhena Kelestyn \\ Warwick Business School \\ Phd13bk@mail.wbs.ac.uk
}

\author{
Ola Henfridsson \\ Warwick Business School \\ Ola.Henfridsson@wbs.ac.uk
}

\author{
Joe Nandhakumar \\ Warwick Business School \\ Joe.Nandhakumar@wbs.ac.uk
}

\begin{abstract}
Digital ventures seek to scale their user base quickly and effectively across markets in order to lock out competitors and drive adoption through positive feedback loops. We view such rapid global scaling as an organising logic by which ventures replicate a generic solution to recurring challenges, that are found in expanding a user base across markets; which is usually characterized by slight variables in their conditions. We distinguish and describe this as a process of "generative pattern replication", where an existing scaling pattern is specialised to the specific circumstances of the new market, and applied there. For our study we looked at BlaBlaCar, a ridesharing venture that has rapidly scaled its business into 22 markets, to gain a better understanding about this generative process. Our research contributes to the digital innovation literature by proposing a novel perspective on the scaling of digital ventures.
\end{abstract}

\section{Introduction}

The user base, that is, the number of users who have registered for a service, is often used as a key indicator of success for digital ventures [21, 41]. Since it assigns weight and legitimacy to a new digital service, the velocity of user base growth [28, 30, 34, $38,41]$ is a major interest point for any digital venture. For instance, since its inception in 2009, Uber scaled its user base to 8 million members in 67 countries [20]. Similarly, Airbnb reached 60 million users in 190 countries [2].

As unprecedented scaling dynamics become more commonplace, the industrial-age understanding of scaling becomes less relevant [45]. Traditionally, scaling was often associated with acquiring new resources to expand the capacity of a business to meet increases in demand [29, 33]. It involved reducing the cost of production, and a core element in achieving "economies of scale" was to standardise production to drive down marginal cost $[1,9]$.
Prior research on rapid scaling of the user base of digital ventures focused on the underlying mechanisms within a single regional market, producing explanations for how to build and sustain momentum [21]. However, many digital ventures are driven by "winner-takes-it-all" perceptions [11, 19, 32], which leads them to seek rapid scaling across several markets. This in turn brings about the challenge of how to expand successfully to a global foothold, whilst knowing that many markets exhibit (slightly) different characteristics. As our understanding of digital innovation develops [10, 22, $44,45]$, it's important to understand more about the processes behind digital ventures' capacities to scale. Thus, this research addresses the following research question:

What is the process by which digital ventures scale their user base across market boundaries?

The approach pertinent to our research is that of scaling via replication, following a digital organising logic, as opposed to the industrial-era logic of scaling via resource acquisition [cf. 29]. To this end, we provide a case study of BlaBlaCar, a ridesharing service, which scaled to 25 million users across 22 markets within 9 years. This case serves as the empirical grounding in which to develop a process model of scaling through "generative pattern replication", wherein an existing pattern is specialised to the local circumstances and then leveraged to scale effectively.

A digital venture attains and improves such a scaling pattern through repeated application of a replication process: transfer a successful digital service to a new market, then adapt it to the specific local conditions, without redefining the service, and focus on scaling the user base. Once such a process has been repeated a few times, it forms a generic pattern that can be applied, and be further improved, when confronted with a new market.

Leveraging such an emergent pattern allows a digital venture to scale rapidly through replication, without the need to reinvent the wheel in each new market. This is enabled by digital infrastructure and the specifics of digital technology, and thus a 
departure from traditional scaling strategies. Hence, our research is a contribution to the digital innovation literature. It proposes opportunities not only for research, but also actionable knowledge for growing successful digital ventures.

\section{Conceptual grounding}

\subsection{Scaling}

Chandler [9] offers rich accounts of industrial age firms and their scaling logic. Scaling of firms such as General Motors (GM) required substantial up-front investment for it to build the infrastructure that would support the scaling efforts of an industrial age firm. Scaling and growth, as described by the industrial-age logic in $[8,9,24,39]$, emphasise driving down unit cost of production to gain competitive advantage [40].

The scaling of ventures such as BlaBlaCar and Airbnb, suggests a different approach to scaling logic; as they required considerably less time to scale in comparison to industrial ones. For example, both BlaBlaCar and Airbnb expanded into their first foreign markets three years after their founding, whereas it took GM fifteen years. Likewise, BlaBlaCar reached twenty million users in nine years, and Airbnb amassed sixty million users in only eight years, while GM again lagged behind, and needed thirty years to have produced twenty million cars, and another fourteen years to hit the fifty million mark [2, 4, 20].

One of the starting-point of this paper is that this difference in scaling can be traced to how digital ventures draw on already existing digital infrastructures [cf. 21]. Rather than making significant investments in proprietary production technologies and distribution systems, in order to reach economies of scale [9], digital ventures are able to exploit existing digital infrastructures. They focus on amassing a large user base at speed, in a bid to disrupt the market and lock out competition. This is possible since the costs of reproducing digital technology, once the initial design is developed, become negligible [7]. Furthermore, the modular and layered architecture of digital technology $[18,45]$ creates infinite opportunities for flexible configurations and customisations. It creates possibilities for cheaply modifying existing technologies when and where needed to sustain growth. Digital technology has therefore had a huge impact on organisations, their strategies [45], and their ability to scale rapidly [21]. This impact extends beyond the industrial-age logic to explain scaling, requiring new approaches suitable for the digital age [26, 31].

Industrial theories of scaling and competitive advantage rely on a firm's ability to find and acquire costly to copy inputs for production and distribution.
Unlike tangible assets, their digital counterparts incur costs merely at the design stage not during reproduction and distribution [35]. Moreover, digital technologies have no natural capacity limits for copies. The foundation of a competitive advantage, then, is not in driving down production costs, but rather finding a superior design, then being able to diffuse it rapidly on a global scale, that allows for the perfecting of the design during scaling.

\subsection{Network effects as motivation for scaling}

One of the motivations for rapid growth is the prospect of network externalities, derived from the user base $[17,25,32,36,37]$. Many digital ventures are in a hurry to scale because the power of network effects helps to achieve and sustain growth that is selfreinforcing. Once the number of users who adopt the digital technology reaches a critical point, the value of that platform for potential users increases rapidly. This creates positive feedback loops and incentives for their existing users to stay, and others to join become high, all whilst creating less room for competition [12, 13]. Gaining the momentum of network effects in digital ventures such as Uber and Airbnb might mean longer lead times, but these are then followed by explosive growth (sometimes referred to as 'hockey stick' growth trajectories). As such, scaling in digital ventures is a strategic imperative, but not to for the achievement of the production side economies of scale, but for the demand side economies of scale, granted through the network effects [35].

Because of such long lead times, and the significance of the user base, profit, or other financial metrics, which are often used to measure the success of a traditional business, do not reflect the true value of a digital venture. It is foreseeable that for a continued period of time it may operate at a loss, on the promise of explosive growth and subsequent profit generation later. Thus, the size of a user base is an important success metric, especially when it comes to digital technology that bank on network effects [25].

\subsection{Scaling via replication}

When viewing scaling from a global perspective, digital ventures are faced with a task of meeting local user needs fast whilst maintaining a competitive global product and a coherent brand. Schilling [32] looked beyond idiosyncratic forces in locking out competitive technologies, to be able to secure winner take all market dominance (specifically modelling and prediction). The author highlights the significance of a "hidden order underlying a complex system" [32, p.395] in an organisation that allows the leveraging of information 
and knowledge in a way that creates opportunities for modelling and prediction. Leveraging a system of previously proven successful and generic solutions, and then applying them to recurring problems in varied market conditions is a challenge digital ventures are faced with when scaling across boundaries.

The nature of digital products and services at its core is almost a prerequisite for replication. The properties of digital technology create very favourable conditions and incentives for ventures to scale rapidly by replication. A working digitally powered idea, once gained proof of concept, can be replicated globally with almost instant market domination. Previously mentioned examples of Uber and Airbnb quickly proved sustainable ways of meeting user needs with digital technology, and replicated the same business model globally, whilst precisely nailing down local demand specificities.

Replication as a business strategy has previously been explored and advocated in the work of Winter and Szulanski [43], who build their replication arguments on very tangible, chain and franchise like businesses, using examples such as [6], who explains cloning of units in chains, and [33] who describes the case of adaptation and tuning of the model with traces of the origins of the concept.

Winter and Szulanski [43] contrast two views on replication: exploitation and exploration and highlight them as two phases of replication. Exploitation, that is, repeated replication of a simple recipe or formula, which is assumed to be known and reproduced accurately each time it is replicated [43, p.730]; and exploration, whereby a business model is discovered and refined by choosing the components for replication in suitable locations, developing capabilities to routinize knowledge transfer, and maintaining the model once it has been replicated [43, p.731]. The transition between the two is a critical point of creating capabilities that support the replication processes and activities to follow.

Organisational theory suggests that replication is difficult and therefore organisations tend to merely adapt to the specificities of the market [14]. Nevertheless, [33] distinguished between firm's adaptive responses and creative responses. The latter are more likely to be innovation-driven and not just adaptations to the market specificities. Weick [42] however suggested that a firm's ability to influence, construct or enact its environment is dependent on the size. The notion of size in the context of digital ventures, in particular in their early days, has a different connotation than the industrial scaling logic, whereby companies exert market power, or rely on economies of scale. In the context of digital ventures that grow by replicating, in order for replication to work it "requires the capability to recreate complex, imperfectly understood, and partly tacit productive processes" [43, p.731]. Therefore, in digital ventures size-related benefits emerge as replication capability evolves with the number of replications, and learning spaces that increase with more markets to replicate into as well as more trials and errors to learn from. With this, the ability to spot and leverage a pattern increases the number of opportunities to scale through replication, in a way that creates complex landscapes of innovation [5] and not just market adaptation.

The capabilities to support the transition exist in forms of knowledge assets codified in frameworks, blueprint, templates, best practices, or according to [43] in a form of a historic template. These have often been used in contexts of global roll-outs of standardised information systems, where organisations face challenges of balancing local needs with global standards, standardisation and flexibility. Building on [27], [43] define a template as a guiding example for reproducing success enjoyed at a particular original setting [43, p.734]. Shapiro and Varian [35] reflect on flexibility of such a pattern as an important aspect of successful replication. A pattern needs to be principled but flexible enough in order to understand the actual core of the success of the business, contrasting with the extreme emphasis on precise replication. In the context of replication in digital ventures, powered by the modular, and malleable nature of technology, ventures extend replication with an aspect of generativity [46] present in the process of scaling through pattern replication.

\subsection{Scaling through generative pattern replication}

Alexander [3] views patterns as responses to problems which occur over and over again in a particular environment. Patterns are generic, and build on specialization; since patterns can be used again and again, without the need for using it the same way twice. Gamma [15], building on this work, defines patterns as "descriptions [...] that are customized to solve a general design problem in a particular context".

In line with Alexander's understanding of the generativity of the patterns, we envision the original 'master' pattern as providing the structure that enables the creation of the 'mutated' patterns in the most appropriate way to the setting and problem they are trying to solve. Each new pattern embodies and carries the structure of the 'master' pattern, despite being a solution that had not be applied before, but within the same framework of guidelines that form a generative structure of the pattern. This enables teams to create their own solutions when solving problems in an infinite variety of ways, replicating broad ideas and components instead of specific solutions. Alexander [3] argues that 
generative patterns are not just collections of good ideas and practices, but rather coherent structures that allow to generate coherent entities and solutions.

The balance of structure and guidelines with innovation and creativity is central to Alexander's way of thinking about generative patterns. Based on this we believe a generative scaling pattern is both generic and specific at the same time, and can create indefinite recombination possibilities. The pattern, once attained, introduces an element of standardisation to the replication process and can help to allocate resources and make strategic decisions that are more effective over time, whilst preventing unnecessary duplication of efforts. Instead of designing resource-consuming strategies for each country, elements of the pattern could be used as tools to draw the necessary resources together. Furthermore, the more markets the pattern was used to expand into, and learnt from, the better the pattern can become. Experiences and learnings that evolve with scaling are documented and formalised then fed into the scaling pattern.

On the other hand, patterns translated for local demands increase the number of possible solutions and innovations available at any point in time. This can help deliver novel, fast and effective responses to an emerging opportunity, even in a non-existing market. Patterns not only serve as a basis for localised decision making, but also as a tool for unlocking innovation opportunities, for teams and individuals, regardless of their expertise and experience. Documented patterns can allow organisations to bridge a gap in understanding for non-experts and experts shuffled in a matrix structure. This is crucial in the increasingly multicultural environment digital ventures operate in, where challenges of coordination collide with the need to retain the start-up culture and team agility. Generative pattern replication distributes the power to innovate beyond top decision makers.

\section{Methods}

We have carried out an in-depth study of a ridesharing venture called BlaBlaCar. During this study BlaBlaCar boasted a user base of twenty-five million members that doubled last year. Since company's expansion into its first foreign market in 2009, BlaBlaCar rapidly grew into twenty-two countries, through a mix of acquisitions, and new market entries, spanning across three continents. We selected BlaBlaCar as an extreme case [16] because of its rapid scaling in an international context. BlaBlaCar also represents a new breed of digital ventures with similar growth trajectories, such as the previously mentioned AirBnB and Uber. This offers opportunities for generating findings and theory that can help explain the user base scaling mechanisms of other digital ventures. Further to this, we gained access to the company and were presented with an opportunity to collect rich primary data, which we supplemented with secondary data, spanning our data analysis across three sources: interviews, archival data and participant observation.

Rapid scaling does not allow for a constant organisational structure, but current teams are divided into Members Relations, Growth, Tech, New Business, Product, Communications, Marketing \& Design, and Admin. Within this division there are local and global teams split based on their activities as either being on the ground on a day to day basis, or offering support and coordination to local teams within global strategic vision. At the time of data collection there were twentytwo local teams spread across fifteen countries. We conducted fifty-eight semi structured, audio taped interviews with country managers, members of local and global teams.

Archival data included reports and project descriptions, as well as various company internal and external presentation material. In addition, the researcher spent four months in the organization as a participant observer, attending meetings, workshops, presentations, and training sessions. During this time several informal interviews were also conducted.

Following [23] theorisation from process data we conducted several stages of data analysis, mapping out tasks and outputs for each respective stage. We began by filtering and labelling the data with open coding. This has allowed us to trace instances of pattern and replication. We then constructed a case narrative to depict the evolution of the replication logic at BlaBlaCar, identifying three phases. We further explored the data with selective coding to understand the linkages between different elements of pattern replication. Through this we arrived at the current visualisation of the process of scaling of user base through pattern replication, initiating explanations of several elements of generative pattern replication.

\section{The case of ridesharing}

BlaBlaCar is one of the digital pioneers of ridesharing that successfully built a marketplace for passengers wishing to travel and drivers with empty car seats on long distance trips. This niche service quickly established a foothold in the native French market, that grew into a single European marketplace, and eventually into Asia and Latin America. Figure 1 shows the numerous diverse markets BlaBlaCar entered since its inception in 2006.

The marketplace was achieved by a mix of acquihiring, that is taking over small European ridesharing startups, whilst hiring the entire teams (e.g. Superdojazd 
in Poland or Rides in Mexico), as well as launching clusters of geographically and culturally similar countries with high levels of cross border trips (e.g. Podorozhniki in Ukraine and Russia or AutoHop in Hungary, Croatia, Serbia and Romania). A number of markets were also built up from scratch (e.g. Spain, UK, Germany).

By tracing the events that preceded global ridesharing success, we create a scaling timeline consisting of three phases. Phase 1 (2006-09) was bracketed as a garage phase where the product was incepted, highlighting a period of development of the core of the business model. Phase 2 (2010-2013) indicates first instance of cross boundary knowledge transfer and business model replication - into Spain, as well as rapid scaling into another nine markets in Western Europe with monetisation bottlenecks. Phase 3 (2014- ongoing) is characterised by replication outside of business model tested Western Europe into Eastern Europe, Asia and Latin America, fuelled by large fundraising episodes. In this phase we observe monetisation, and booking system replication as more weighted and rolled out in stages as a result of leveraging and transferring of the stock of knowledge accumulated from previous monetisation and booking replications.

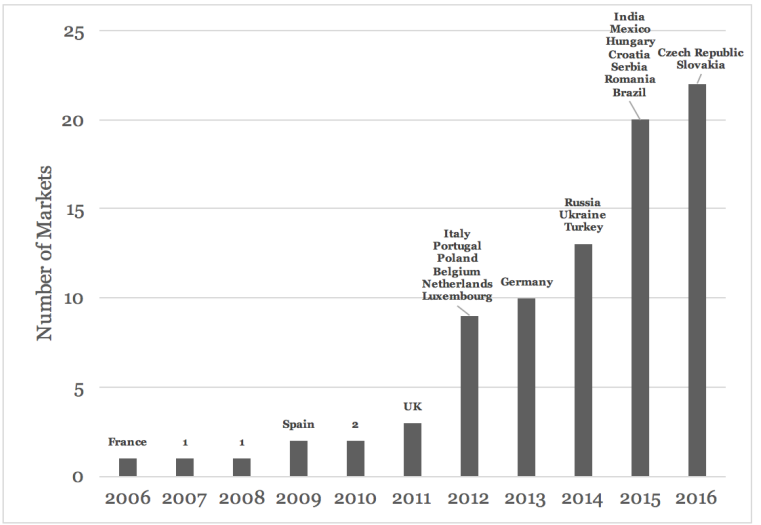

Figure 1. Market growth timeline

Phase 1 (2006-2009) commenced with a launch of the company Covoiturage, and the first website. This phase can be described as a 'garage phase', where the concept of online ridesharing was being refined. Covoiturage enjoyed organic growth with little investment and effort, based on the attractiveness of the digitally enabled ridesharing. The main focus of the phase is the development of the core of the product:

"There was a three to four-year garage phase, right, where things weren't quite right yet. I think ratings for instance were introduced in 2009 which speaks to having the right product, right. It takes time to have really the product that is going to crack the market...", Growth Team Member.
The service started gaining momentum in 2007, when a series of transport industry strikes left few other travel options for the French public and a large number of signups created positive liquidity, matching between drivers and passengers and their travel plans. This was the turning point in the development of BlaBlaCar. This demand spike led to the opening of their first office in Paris, and subsequent hiring of their first employee in 2008.

An initial consumer to consumer (C2C) offering was expanded into a business to business (B2B) platform, selling services to local companies and authorities. B2B quickly became a source of revenue in contrast to a free C2C platform, which on the other hand was growing faster with fewer resources. Despite the profitability, $\mathrm{B} 2 \mathrm{~B}$ required high client customisation and this had little scalability potential, making BlaBlaCar rethink the business model. BlaBlaCar spotted positive feedback loops that would allow rapid growth to their user base in both France and internationally, as to redirect its focus entirely to scaling the $\mathrm{C} 2 \mathrm{C}$ platform. Scalability becomes the centre of the team's focus:

"[We] realized that C2C marketplace is growing much faster and on its own and in a more efficient way with a lot of traction. Much more than the B2B platform that's less scalable with a lot of education, communication skills required...It was a different business model but that's not where the growth is so they needed to make their bets", Global Team Member.

Up until the introduction of the current business model at the end of 2011/early 2012 Covoiturage trialled a series of business model options. The move towards the right business model and 'proof of concept' in France resulted in BlaBlaCar raising $€ 600,000$ in 2009. Following this, with the right product and financial resources, BlaBlaCar was able to launch the first market outside of France:

"And then from having the right product then you start getting traction in the market, investors can see that, they back you with money and suddenly you have the budget to really explode. And also hire people or acquire other teams...", Growth Team Member.

In December 2009 the company announced an expansion to Spain replicating the service and product under the name Comuto, and launched its first mobile application.

Phase 2 (2010-2013). In 2010 further $€ 1.25$ million investment was secured. In the same year European transport infrastructure got shaken up by an eruption of volcano Eyjafjallajökull, causing air travel disruption across Europe and creating a surge in demand, and subsequent high price and low availability of other 'traditional' means of transport. This event created undoubted traffic to the BlaBlaCar website and heightened public and media interest across Europe.

In December 2011 BlaBlaCar received a further investment of $\$ 10$ million. In May 2011 BlaBlaCar 
entered its third market - the UK and reached its first millionth members. At this point the team started seeing patterns of growth, similarities in markets and opportunities for replication of the French market scaling trajectories:

"At the time, we were starting to operate in three countries and we already started to see that we could draw patterns from one country and apply it to another one, find levers that worked somewhere and try them somewhere else. That was the focus at first then you grew around that...", Growth Team Manager.

As a result of drawing on these patterns, the year of 2012 saw rapid expansion across Europe, starting in Italy in May with an acquisition of a local startup PostoinAuto. In October BlaBlaCar launched in Portugal, Belgium, Netherlands, Luxembourg, as well as Poland by acquiring another on the ground start up Superdojazd. The focus on scalability created the need for a stronger international brand. Toward the end of 2012 the company consolidated Covoiturage and Comuto under one global brand and name - BlaBlaCar:

"The first name of the company was Covoiturage, which means ridesharing in French, which is the wrong name because you're never going to expand. So, initially its easy because it's good for SEO, so it's kind of an easy way to start your business as an Internet company, but it doesn't scale, right, so we had to rebrand", COO, speaking at Webrazzi.

BlaBlaCar had on place the product, the team of founders, nine markets, the brand, and the finance, and so they began the project of monetizing the service. The finalised business model, online booking system, was to become transactional, based on an inbuilt booking which levies a fee on each trip. The nature of the system allowed to maximise scalability. More first time users were attracted to a legitimised and governed ridesharing service, as the booking system added a layer of security and trust to the platform. The system simplified the booking process and on board logistics of a ride, reduced cancellations and improved members' commitment. A member of a global team summarises the role of the booking system as follows:

"...Our belief is the more present that we can be as a third party inside that connection, the better it is because we can add value, add confidence, add service layers, add customer support. So everything that we can, any way we can structure the transaction and be present, not just enable but be present throughout that transaction, is a good thing for us", Global Team Member.

The booking systems were first rolled out in France and Spain. The successes and errors from the transition in France and Spain were transferred across other markets, and became the basis for launching all consecutive local systems. A member of a global team emphasises the role of sharing and replication in booking transition:

"...The booking transition in Spain which was the first one after France was a bit difficult to handle because there was a great backlash of the community whereas now we've transitioned many other countries, progressively there was very different strategic approach especially on the Comms side. And what you have seen what is happening currently in Italy is much more smoother actually in terms of change, so we are seeing how much we are sharing more and more really", Global Team Member.

In April 2013 BlaBlaCar stood up to its main European competitor, a local German ridesharing start up, and launched in Germany, announcing five million members.

Phase 3 (2014-ongoing). Shortly after launching Germany, BlaBlaCar makes a decision to step out of Western and Central Europe, and into Russia and Ukraine in February 2014 through the acquisition of Podorozhniki. In summer 2014 an investment announcement was made: $\$ 100$ million would be made available to bankroll BlaBlaCar's expansion into Asia and South America. Company launches its first country outside Europe - Turkey in September 2014 and announces plans to launch India, Mexico, and Brazil. At this point BlaBlaCar boasted $200 \%$ year on year growth, with 10 million registered users. Continuing with monetization many other countries have initiated the switch to online booking, which in terms of both the product features and the roll out process was altered in light of every previous booking system launch. As a result, several booking system configurations were developed to suit the local needs and market intricacies and many countries begun the monetization with a nonpayment booking system, preparing the community for a smooth introduction of the payment:

"So the challenge here is really to prepare this in the right way so there's a lot of work planned maybe a year ahead to, especially in terms of payment ..., we want to scale as much as we can and to have one product that scales everywhere in the world as much as we can, but when it comes to payment it's just very country-specific", Global Team Member.

In September $2015 \$ 200$ million were raised, which allowed BlaBlaCar to launch in India in January 2015; the following month the acquisition of AutoHop and further expansion into Eastern Europe took place (launching Hungary, Croatia, Serbia and Romania, in March of that year). In April BlaBlaCar announces merger with a German competitor - Carpooling, transforming it into largest long distance ridesharing service in Europe and the world.

In the same month, BlaBlaCar acquired Rides and launched Mexico whilst UK was being transferred to the online booking system, making it the third country to monetize. For the rest of the markets the gradual switch to the booking system was ongoing. The platform created by the booking system had opened multiple partnership and service extension opportunities for BlaBlaCar, such as one with global insurance giant AXA, offering additional insurance for all members, 
rapidly increasing the value to users, boosting trust and attracting older demographic to the service. A global team member comments on the value of the booking system:

"In that sense, in itself, [booking system] brings a lot of value and on top of that we can track and we can have a lot of knowledge then you can get many other things on top of it. Partnerships, extended business lines, extended services...", Global Team Member.

Later that year BlaBlaCar received a $\$ 1.6$ billion valuation making it one of the Unicorn club companies, putting it alongside giants such as Uber, Airbnb, Spotify and Skyscanner. November 2015, another Latin American country was launched - Brazil, and in early 2016 BlaBlaCar announced it launching Czech Republic and Slovakia.

\section{Scaling through pattern replication}

What can be traced from the case story is a gradual introduction of replication of learnings into global projects adjusted for local demands, such as in the example of their booking system and monetization roll out. The spotting and leveraging of patterns comes through initially in early country launches, in the consolidation towards a global recognisable brand, and in the search for a booking system with the maximum capacity to scale across boundaries.

We traced several elements that form a structure for replication at BlaBlaCar. We found that scaling through pattern replication rests on three pillars: artifact, flexible organising, and value framing.

A successful scaling strategy or technique gets reapplied, and becomes a pattern that can be replicated in other settings. Learnings from applying a pattern are captured as a framework in a playbook, and in this way disseminated across all teams.

"Playbook is basically the know-how through trials and errors and successes that's been formalised into a set of reasonable principles and processes that can be transferred to other teams easily so you can tell them "hey, this is what works/doesn't work, this is the right approach, this is something that might or might not work and this is something that surely won't work", Growth Team Member.

So, the first element of scaling through pattern replication is a physical manifestation of the pattern in the form of an artifact - a playbook. Any team member can access and replicate a pattern from a playbook, using it as a tool. Best practices in replicating a pattern are fed back to the playbook constantly and a pattern is then further circulated into multiple new versions of the pattern in local markets. The playbook acts as a conversion tool that allows the teams to process local learning into shared global best practices, that can then be adapted locally: either across boundaries or in the market where it originated as an advanced version of the original solution.

The playbook embodies the pattern and serves as a carrier for knowledge, but it is only an extension of the learnings, held by 'experts' that have previously and successfully replicated a pattern. Replication becomes possible with high market and team mobility, required to pull resources when replicating the pattern effectively and rapidly. So, the second element of scaling through pattern replication is flexible organising - agile team structuring that allows to maintain a level of synchronisation across teams and boundaries, allocating patterns and team resources where they are needed most. Building on the playbook and the leveraging of agile teams allows to balance new business opportunities with growth of existing projects, local and global growth context, the need for operational, day to day running of the business with forward looking innovation strategizing.

"So when building something you actually think that it should be scalable. So when structuring the team you will think already that we're going to grow and you think "okay, so when we are going to be fifty how like would these processes be applicable or not". So can I build such processes which would be applicable now as well as in ten years, you know, it's something like that. And if your answer is 'no' then you should take this into consideration and take into account that "OK, now I am building something for one year, in one year we will need to change”, but ideally you try to find a way which would be scalable and applicable for twenty people, as well as thirty, as well as fifty", Growth Team Member.

The third element, value framing, is comprised of 10 values, drawn up internally by the team, that govern everyday practices and processes in the organization. Values create a common 'language' and decision making reference point that facilitates boundary crossing and replication.

"I mean the values are very much like... kind of prophecies you can point to... I remember I was speaking to one of the senior guys here and I was struggling working with maybe 5 people in a cross project and also across a few countries and they deal with like 30-40 people. I'm like "how do you bring everybody to consensus without just saying 'no, this is the way it's going to be?" And he just pointed to the values and said you nudge them and in doing that everyone feels equal and there isn't so much of like a sort of residue of politics...", Global Team Member.

Artifact, flexible organising and value framing create generic guidelines, a 'safety net' for replicating the pattern, in an autonomous way, on individual and company level, globally and locally, but within the overall company strategy and vision.

"...we need to spend a lot of time understanding how to prioritise. So making sure that all markets get what they need. And beyond that it also requires us to set up frameworks. So rather than having a set, you know, set of rules, we actually set a framework that countries can adapt to their local needs", Growth Team Member. 


\section{Discussion and conclusions}

The unique nature of digital technology [45], leveraged by digital ventures as they seek to address the needs of users, seems to trigger soaring scaling trajectories that lie outside our conventional understanding of economics of scale [cf. 9]. Stimulated by winner-takes-it-all perceptions [11, 32], digital ventures attempt to scale rapidly across market boundaries displaying varied market conditions. As this phenomenon becoming more common, we need to enrich our understanding of scaling in the digital age, especially across market boundaries. To this end, we studied BlaBlaCar, which scaled its business into twenty-two markets in roughly ten years' time. We view this scaling as a process of pattern replication successful strategies proven elsewhere, applied in solving emerging challenges in new settings. Our research aimed to trace this process, understand it and propose a model to explain it.

Our research at BlaBlaCar uncovered the process and its elements by which digital ventures can extract and leverage patterns in scaling its user base across boundaries. The main contribution is the process model of Scaling through Generative Pattern Replication (see Figure 2) that offers a novel perspective on scaling of digital ventures.

Figure 2. A process model of scaling through generative pattern replication

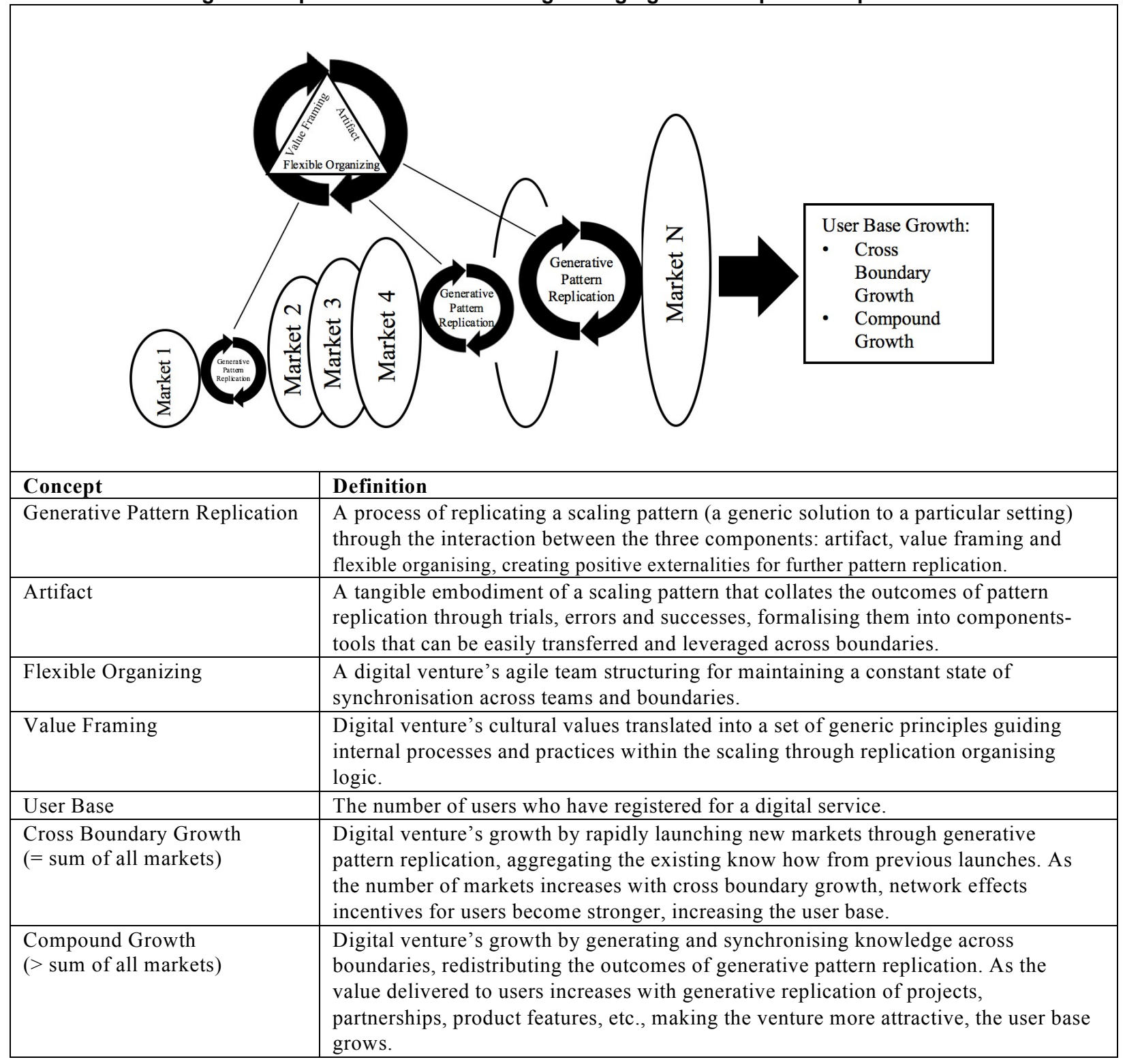


These patterns consist of components of different nature: physical artifact, serving as a shared resource used to collate the learnings when replicating patterns; agile team structure reflected in flexible organising that ensures cross team synchronisation when replicating; value framing that leverages venture's cultural values to guide decision making, and maintain the teams focus on the scalability of replication.

We understand generative pattern replication's (GPR's) impact on the growth of the user base in two ways: through cross boundary growth, which allows digital ventures to launch new markets quickly by leveraging the patterns, but also compound growth; increasing the value to the users, as each market from the outset contains the patterns from all other markets. When combined, these extend the size of the user base in terms of the number of markets, (creating stronger network effects,) and shared knowledge, (attracting user by delivering more value faster.).

We contribute to the emerging literature on digital innovation [e.g., 44, 45] by offering a novel explanation of the processes that underpin digital ventures' ambitions to scale their user base rapidly through GPR, as exemplified in the case of BlaBlaCar. We highlight that replication as a strategy [43] essential for the growth of the digital venture. Rather than simply relying on adaptation to market conditions, our approach involves leveraging coherent structures [3] that evolve with size and replication, allowing digital ventures to create innovation opportunities, whilst solving daily challenges, thorough the process of GPR.

Additionally, we contribute to the understanding of user base growth [21] by outlining the process by which digital ventures can overcome market variation internationally, conceptualizing this growth as multidimensional and as increasing the knowledge transferred between the markets through replication.

There are a few limitations of the research. First, our research builds on an in-depth case study. Future research should consider including a wider variety of cases to allow for comparative analysis. Furthermore, it would have been useful to have access to more powerful data on the dependent variable, that is, user base. This would have allowed more careful analysis of how particular replication acts influenced the scaling process. Further research, with access to a more comprehensive dataset on the user base across time, might be able to trace variation in the replication acts and offer a dynamic theory of this interesting phenomenon.

\section{References}

[1] Abernathy, W.J. and J.M. Utterback, "Patterns of Industrial Innovation”, Technology Review, 80(7), 1978, pp. 41-47.

[2] Airbnb, 2016. About Us. https://www.airbnb.co.uk/about/about-us, accessed 9-222016.

[3] Alexander, C., "The Origins of Pattern Theory: The Future of the Theory, and the Generation of a Living World", IEEE Software, 16(5), 1999, pp. 71-82.

[4] Blablacar, 2016. About us. https://www.blablacar.co.uk/about-us, accessed 9-22-2016.

[5] Boland, R.J., K. Lyytinen, and Y. Yoo, "Wakes of Innovation in Project Networks: The Case of Digital 3-D Representations in Architecture, Engineering, and Construction”, Organization Science, 18(4), 2007, pp. 631647.

[6] Bradach, J.L., "Using the Plural Form in the Management of Restaurant Chains", Administrative Science Quarterly, 42(2), 1997, pp. 276-303.

[7] Brynjolfsson, E. and A. Saunders, Wired for Innovation: How Information Technology Is Reshaping the Economy, MIT Press, Cambridge, MA, 2009.

[8] Chandler, A.D., Strategy and Structure: Chapters in the History of the American Industrial Enterprise, MIT Press, Cambridge, MA, 1962.

[9] Chandler, A.D., Scale and Scope: The Dynamics of Industrial Capitalism, The Belknap Press of Harvard University Press, Cambridge, MA, 1990.

[10] Eaton, B., S. Elaluf-Calderwood, C. Sørensen, and Y. Yoo, "Distributed Tuning of Boundary Resources: The Case of Apple's iOS Service System”, MIS Quarterly, 39(1), 2015, pp. 217-243.

[11] Eisenmann, T., G. Parker, and M.W. van Alstyne, "Strategies for Two-sided Markets", Harvard Business Review, 84(10), 2006, pp. 92-101.

[12] Evans, D.S., "How Catalysts Ignite: The Economics of Platform-based Start-ups", in Platforms, Markets, and Innovation, A. Gawer, Editor. 2009. Edward Elgar: Cheltenham, UK.

[13] Evans, D.S. and R. Schmalensee, "Failure to Launch: Critical Mass in Platform Businesses", Review of Network Economics, 9(4), 2010, pp. 1-26.

[14] Florida, R. and M. Kenney, "Transfer and Replication of Organizational Capabilities: Japanese Transplant Organisations in the US", in The Nature and Dynamics of Organizational Capabilities, G. Dosi, R.E. Nelson, and S.G. Winter, Editors. 2000. Oxford University Press: Oxford.

[15] Gamma, E., R. Helm, R.E. Johnson, and J. Vlissides, Design Patterns: Elements of Reusable Object-Oriented Software, Addison-Wesley, Reading, MA, 1995.

[16] Gerring, J., Case Study Research: Principles and Practices, Cambridge University Press, Cambridge, 2007.

[17] Grisot, M., O. Hanseth, and A.A. Thorseng, "Innovation of, in, on Infrastructures: Articulating the Role of Architecture in Information Infrastructure Evolution", Journal of the Association for Information Systems, 15(4), 2014, pp. 197-219. 
[18] Henfridsson, O., L. Mathiassen, and F. Svahn, "Managing Technological Change in the Digital Age: The Role of Architectural Frames", Journal of Information Technology, 29(1), 2014, pp. 27-43.

[19] Hill, C.W.L., "Establishing a Standard: Competitive Strategy and Technological Standards in Winner-Take-All Industries", The Academy of Management Executive, 11(2), 1997, pp. 7-25.

[20] History, 2016. 1967: GM Celebrates 100 Millionth U.S.-made Car. http://www.history.com/this-day-inhistory/gm-celebrates-100-millionth-u-s-made-car, accessed 9-22-2016.

[21] Huang, J., O. Henfridsson, M.J. Liu, and S. Newell, "Growing on Steroids: Rapidly Scaling the User Base of Digital Ventures Through Digital Innovation”, MIS Quarterly(forthcoming), 2016.

[22] Kallinikos, J., A. Aaltonen, and A. Marton, "The Ambivalent Ontology of Digital Artifacts", MIS Quarterly, 37(2), 2013, pp. 357-370.

[23] Langley, A., "Strategies for Theorizing from Process Data”, Academy of Management Review, 24(4), 1999, pp. 691-710.

[24] Langlois, R.N., The Dynamics of Industrial Capitalism: Schumpeter, Chandler, and the New Economy, Routledge, London, 2007.

[25] Lee, E., J. Lee, and J. Lee, "Reconsideration of the Winner-Take-All Hypothesis: Complex Networks and Local Bias”, Management Science, 52(12), 2006, pp. 1838-1848.

[26] Lyytinen, K. and Y. Yoo, "Research Commentary: The Next Wave of Nomadic Computing", Information Systems Research, 13(4), 2002, pp. 377-388.

[27] Nelson, R.R. and S.G. Winter, An Evolutionary Theory of Economic Change, Belknap Press of Harvard University Press, Cambridge, MA, 1982.

[28] Oliva, R., J.D. Sterman, and M. Giese, "Limits to Growth in the New Economy: Exploring the 'Get Big Fast' Strategy in E- commerce”, System Dynamics Review, 19(2), 2003, pp. 83-117.

[29] Penrose, E.T., The Theory of the Growth in the Firm, Blackwell, Oxford, 1959.

[30] Prasad, A., R. Venkatesh, and V. Mahajan, "Optimal Bundling of Technological Products with Network Externality", Management Science, 56(12), 2010, pp. 22242236.

[31] Sambamurthy, V. and R.W. Zmud, "Research Commentary: The Organizing Logic for an Enterprise's IT Activities in the Digital Era-A Prognosis of Practice and a Call for Research", Information Systems Research, 11(2), 2000, pp. 105-114.

[32] Schilling, M.A., "Technology Success and Failure in Winner-Take-All Markets: The Impact of Learning Orientation, Timing, and Network Externalities", The Academy of Management Journal, 45(2), 2002, pp. 387-398.

[33] Schumpeter, J.A., "The Creative Response in Economic History", The Journal of Economic History, 7(2), 1947, pp. 149-159.

[34] Shankar, V. and B.L. Bayus, "Network Effects and Competition: An Empirical Analysis of the Home Video Game Industry", Strategic Management Journal, 24(4), 2003, pp. $375-384$
[35] Shapiro, C. and H.R. Varian, Information Rules: A Strategic Guide to the Network Economy, Harvard Business School Press, Boston, MA, 1999.

[36] Song, M., M.E. Parry, and T. Kawakami, "Incorporating Network Externalities into the Technology Acceptance Model", Journal of Product Innovation Management, 26(3), 2009, pp. 291-307.

[37] Suarez, F.F., "Network Effects Revisited: The Role of Strong Ties in Technology Selection", The Academy of Management Journal, 48(4), 2005, pp. 710-720.

[38] Sun, B., J. Xie, and H.H. Cao, "Product Strategy for Innovators in Markets with Network Effects", Marketing Science, 23(2), 2004, pp. 243-254.

[39] Teece, D.J., "The Dynamics of Industrial Capitalism: Perspectives on Alfred Chandler's Scale and Scope", Journal of Economic Literature, 31(1), 1993, pp. 199-225.

[40] Tirole, J., The Theory of Industrial Organization, MIT Press, Cambridge, MA, 1998.

[41] Tucker, C. and J. Zhang, "Growing Two-Sided Networks by Advertising the User Base: A Field Experiment", Marketing Science, 29(5), 2010, pp. 805-814.

[42] Weick, K.E., The Social Psychology of Organizing, $2^{\text {nd }}$ edn., McGraw-Hill, New York, 1979.

[43] Winter, S.G. and G. Szulanski, "Replication as Strategy", Organization Science, 12(6), 2001, pp. 730-743.

[44] Yoo, Y., R.J. Boland, K. Lyytinen, and A.

Majchrzak, "Organizing for Innovation in the Digitized World", Organization Science, 23(5), 2012, pp. 1398-1408.

[45] Yoo, Y., O. Henfridsson, and K. Lyytinen, "The New Organizing Logic of Digital Innovation: An Agenda for Information Systems Research", Information Systems Research, 21(4), 2010, pp. 724-735.

[46] Zittrain, J.L., "The Generative Internet", Harvard Law Review, 119(7), 2006, pp. 1974-2040. 